\title{
Arousal in patients with gastro-oesophageal reflux and sleep apnoea
}

\author{
T. Penzel, H.F. Becker, U. Brandenburg, T. Labunski, W. Pankow, J.H. Peter
}

\begin{abstract}
Arousal in patients with gastro-oesophageal reflux and sleep apnoea. T. Penzel, H.F. Becker, U. Brandenburg, T. Labunski, W. Pankow, J.H. Peter. (C) ERS Journals Ltd 1999. ABSTRACT: Nocturnal gastro-oesophageal reflux has been observed in patients with obstructive sleep apnoea (OSA). Negative intrathoracic pressure during apnoeas and arousal have been suggested as the underlying mechanisms.

In order to evaluate this hypothesis, the coincidence and sequence in time of arousal, apnoea and reflux events were analysed. Fifteen patients with OSA or heavy snoring were studied by means of standard polysomnograpy with parallel recording of 24-h oesophageal pH.

Reflux events during the day were present in all patients, five of whom had symptoms of reflux. In three of these and in five other patients, a total of 69 nocturnal reflux events were found. In 68 events, arousal was found with the reflux event. Only one reflux without arousal was found (sleep stage 2). Seventeen events occurred during wakefulness after sleep onset. The percentage of time with a $\mathrm{pH}$ of $<4$ during wakefulness after sleep onset was significantly higher than the percentage of time with a $\mathrm{pH}$ of $<4$ during total sleep time $(p<0.05)$. In 37 of the 52 reflux events which occurred during sleep, either an apnoea or a hypopnoea was found prior to the event. The investigation of sequence in time did not prove a causal relation between respiratory events and reflux events.
\end{abstract}

The results indicate that gastro-oesophageal reflux and obstructive sleep apnoea are two separate disorders, which both have a high prevalence in obese patients.

Eur Respir J 1999; 14: 1266-1270.
Medizinische Poliklinik, Philips-Universität, Marburg, Germany.

\section{Correspondence: T. Penzel}

Medizinische Poliklinik der Philips-Universität

Baldingerstr. 1

D-35033 Marburg

Germany

Fax: 4964212865450

Keywords: Arousal

gastro-oesophageal reflux

$\mathrm{pH}$ recording

polysomnography

sleep apnoea

Received: April 231998

Accepted after revision June 291999
Gastrooesophageal reflux disorder is characterized by an increased number and duration of gastro-oesophageal reflux events [1]. An underlying reflux disease is assumed if the percentage of time with a $\mathrm{pH}$ of $<4$ in the upright position $>10.5$ or if the percentage of time with a $\mathrm{pH}$ of $<4$ in the supine position $>6$ [2]. The prevalence of gastrooesophageal reflux disorder is $5 \%$ of the adult population [3], and thus is similar to the prevalence of sleep-related breathing disorders [4]. In healthy adults, very few gastrooesophageal reflux events are found during the night (eight times less than during the daytime) [5-7]. In patients with a gastro-oesophageal reflux disease, in addition to daytime events, nocturnal events are also found. Nocturnal gastro-oesophageal reflux is clinically very important because events usually last longer than during the daytime. This is due to the fact that oesophageal motility is reduced at night and the supine body position also causes prolonged oesophageal clearance. In addition, the time course of reflux events during wakefulness and during sleep are very different. Typically, $>80 \%$ of the reflux events occur during wakefulness in the upright body position after a meal, and are cleared rather quickly under these conditions. Reports concerning reflux events during sleep differ widely. Some studies report that patients continue to sleep without being disturbed [5] and others report many awakenings [8]. Characteristic reflux symptoms were reported if the patients woke. It is not clear whether reflux usually causes awakenings or only arousal, and furthermore whether arousal may cause reflux. It is known, however, that patients with reflux symptoms during the day also exhibit more reflux events during the night compared to normal subjects [6].

Patients with sleep-related breathing disorders usually experience multiple arousals during sleep, leading to sleep fragmentation and excessive daytime somnolence. Typically, these arousal terminate apnoeas. During obstructive apnoeas, pronounced negative intrathoracic pressure swings are found. It has been assumed that negative intrathoracic pressure provokes gastro-oesophageal reflux [9-10]. KERR et al. [9] reported that the mean percentage of time with a $\mathrm{pH}$ of $<4$ in patients with obstructive sleep apnoea (OSA) decreased from $6.3 \pm 2.1$ before therapy to $0.1 \pm 0.1$ with continuous positive airway pressure with (CPAP). The mechanisms remain unclear. In order to study the mechanisms involved in more detail, the exact sequence in time of sleep stage, arousal and $\mathrm{pH}$ was investigated by means of simultaneous recording of digital polysomnographic data and $\mathrm{pH}$ using a signal processing tool kit, which has not been previously carried out.

\section{Method}

\section{Subjects and protocol}

Fifteen consecutive patients with suspected OSA due to snoring, excessive daytime sleepiness and ambulatory recording were referred to the authors' laboratory for polysomnography. Anthropometric data are presented in table 1. 
Table 1. - Anthropometric data and reported symptoms according to medical history together with $24 \mathrm{~h} \mathrm{pH}$ recording results from all patients

\begin{tabular}{|c|c|c|c|c|c|c|c|c|c|}
\hline \multirow{2}{*}{$\begin{array}{l}\text { Patient } \\
\text { No. }\end{array}$} & \multirow{2}{*}{$\begin{array}{l}\text { Age } \\
\text { yrs }\end{array}$} & \multirow{2}{*}{$\begin{array}{c}\mathrm{BMI} \\
\mathrm{kg} \cdot \mathrm{m}^{-2}\end{array}$} & \multirow{2}{*}{$\begin{array}{l}\text { Reported reflux } \\
\text { symptoms }\end{array}$} & \multirow{2}{*}{$\begin{array}{c}\text { AHI } \\
\text { events } \cdot h^{-1}\end{array}$} & \multirow{2}{*}{$\begin{array}{c}\text { REI } \\
\text { events } \cdot h^{-1}\end{array}$} & \multicolumn{2}{|c|}{$\mathrm{pH}<4 \%$ time } & \multicolumn{2}{|c|}{ GOR n } \\
\hline & & & & & & upright $^{+}$ & supine $^{\#}$ & daytime & night-time \\
\hline 1 & 50 & 31.2 & Yes & 38.0 & 38.0 & 3.7 & $18.9^{*}$ & 22 & 24 \\
\hline 2 & 63 & 38.2 & No & 17.4 & 29.9 & 8.8 & 0.6 & 14 & 0 \\
\hline 3 & 53 & 40.4 & No & 62.8 & 72.1 & 5.3 & 0.6 & 21 & 0 \\
\hline 4 & 47 & 26.8 & Yes & 16.0 & 27.6 & 7.3 & $6.7^{*}$ & 45 & 9 \\
\hline 5 & 66 & 33.8 & No & 0.6 & 23.7 & 4.2 & 0.0 & 17 & 0 \\
\hline 6 & 40 & 37.4 & No & 99.8 & 99.8 & 7.7 & 5.2 & 38 & 3 \\
\hline 7 & 54 & 27.4 & No & 9.0 & 26.5 & 2.8 & 0.6 & 9 & 4 \\
\hline 8 & 53 & 24.9 & No & 10.9 & 26.1 & $33.9 *$ & $7.0^{*}$ & 53 & 3 \\
\hline 9 & 47 & 25.7 & Yes & 19.7 & 24.8 & $72.4 *$ & $22.8 *$ & 118 & 11 \\
\hline 10 & 57 & 27.5 & No & 16.3 & 20.7 & $20.8^{*}$ & 0.5 & 72 & 0 \\
\hline 11 & 56 & 34.8 & Yes & 27.4 & 35.1 & 2.6 & 1.4 & 17 & 0 \\
\hline 12 & 49 & 31.9 & No & 48.5 & 53.9 & 8.3 & $6.6^{*}$ & 45 & 11 \\
\hline 13 & 34 & 35.8 & No & 49.4 & 80.6 & $19.6^{*}$ & 5.7 & 66 & 4 \\
\hline 14 & 53 & 30.2 & Yes & 30.6 & 44.1 & 10.1 & 0.0 & 33 & 0 \\
\hline 15 & 45 & 31.0 & No & 5.3 & 20.1 & 1.9 & 0.4 & 13 & 0 \\
\hline Mean & $51.1 \pm 8.2$ & $31.8 \pm 4.8$ & & $30.1 \pm 26.3$ & $41.5 \pm 24.4$ & $14.0 \pm 18.4$ & $5.1 \pm 7.0$ & $38.9 \pm 29.5$ & $4.6 \pm 6.7$ \\
\hline
\end{tabular}

Mean values are presented as mean $\pm \mathrm{SD} .{ }^{+}:>10.5 \%$ is rated as pathological [2]; ${ }^{*}:>6 \%$ is rated as pathological [2]; *: pathological. BMI: body mass index; AHI: apnoea/hypopnoea index; REI: respiratory event index; GOR: gastro-oesophageal reflux.

All patients were more or less obese. Patients were included in the study irrespective of symptoms regarding gastro-oesophageal reflux. After inclusion, however, reflux-related symptoms were assessed using a specific standardized interview. In all 15 patients who agreed to participate in the study, standard polysomnography and 24-h gastro-oesophageal $\mathrm{pH}$ recording were performed simultaneously.

\section{Measurements}

Polysomnography consisted of the following parameters: two electroencephalograms (EEGs), two electro-oculograms (EOGs), one electromyogram (EMG) submentalis and one electrocardiogram (ECG) recorded on paper charts at $10 \mathrm{~mm} \cdot \mathrm{s}^{-1}$ for visual analysis. In addition, oronasal airflow, thoracic and abdominal respiratory movements (Respitrace; Studley Data Systems, Oxford, UK), laryngeal sound [11], oxygen saturation and cardiac frequency were recorded on a second chart recorder with a paper speed of $1 \mathrm{~mm} \cdot \mathrm{s}^{-1}$ to evaluate apnoeas, hypopnoeas and obstructive snoring. In parallel, all signals were recorded digitally using a computer with a 16-channel analogue/ digital converter at $100 \mathrm{~Hz}$ (Multilab-4 card with 16channel 12-bit module, Sorcus, Heidelberg, Germany). Data were stored on optical disks. An analogue binary coded time signal generated by a microcomputer was recorded on both chart recorders and on the computer. This allowed the simultaneous evaluation of sleep stages, arousal and respiration and thus the exact attribution of any event (fig. 1) [12].

For the continuous recording of $\mathrm{pH}$, a system designed for ambulatory recording was used: Mesa type DL 70 with Ingold $\mathrm{pH}$ sensor type M3 (Mesa, Benediktbeuern, Germany). This recorder allowed the storage of one $\mathrm{pH}$ value every $2 \mathrm{~s}$ for a total recording duration of $25 \mathrm{~h}$. In addition, the system recorded a number of patient-triggered events, such as food intake, symptoms of reflux and the start of recording in the sleep laboratory, coded by different keys on the recorder. On initializing the recording, the internal clock of the $\mathrm{pH}$ recorder was synchronized with the microcomputer-driven clock in the sleep laboratory mentioned above. Afterwards, the recorded data were downloaded using a computer. Evaluation of the recording was performed using the software package of the system (Mesa). Additionally, the recording was converted into a continuous signal. This signal was then integrated with the digital polysomnography after checking the proper synchronization of the clocks. This was accomplished by means of a special computer program, which was interfaced with the modular data format of the digital polysomnography. A cross-check was carried out on the basis of the event marking on both the polygraph and the $\mathrm{pH}$ recorder.

Body position was recorded by the MESA DL 70 recorder and, in addition, was verified by video while the patient was in the sleep laboratory.

\section{Data analysis and statistics}

Sleep stages were evaluated according to RECHTSCHAFFEN and KALES [13] and arousals were scored according to American Sleep Disorders Association (ASDA) criteria [14]. Arousals had to be characterized by alpha or beta waves on the EEG for $\geq 3 \mathrm{~s}$ and not $>15 \mathrm{~s}$, accompanied by an increase in EMG activity. A transition to wakefulness was scored if the frequency increase in EEG waves persisted for $>15 \mathrm{~s}$, and the corresponding epoch was classified as wakefulness. Total sleep time (TST) was calculated as well as wakefulness after sleep onset (WASO).

Apnoeas were scored as a cessation of airflow for $\geq 10$ s. Hypopnoeas were scored as a reduction in airflow to $50 \%$ and oxygen desaturation of $\geq 4 \%$. Obstructive snoring was scored if the microphone recorded noise and oxygen saturation dropped by $\geq 4 \%$. The apnoea/hypopnoea index (AHI; number of apnoeas and hypopnoeas per hour of sleep) and the respiratory event index (REI; number of apnoeas, hypopnoeas and obstructive snoring episodes per hour of sleep) were calculated. 


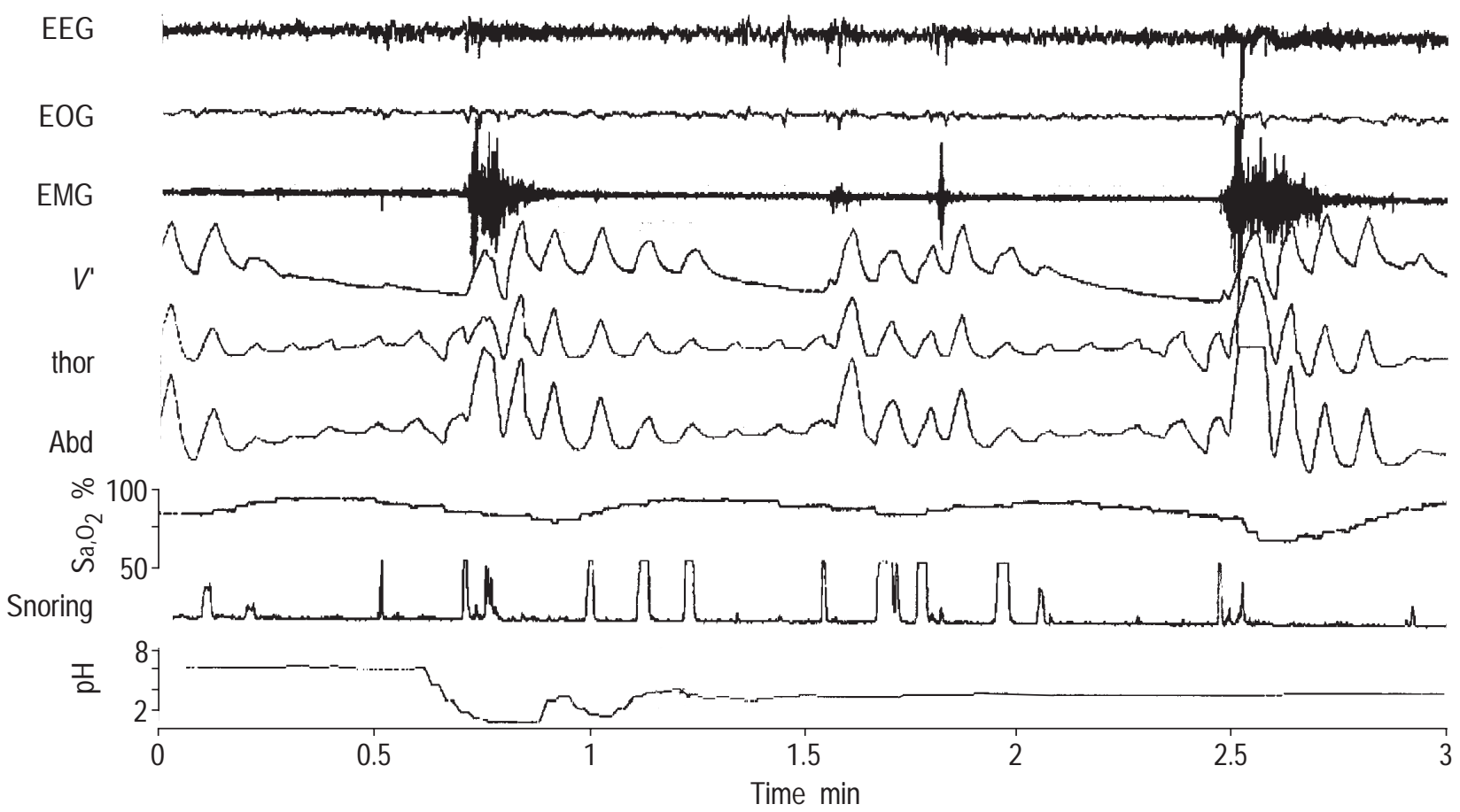

Fig. 1. $-\mathrm{pH}$ recording of a patient with obstructive sleep apnoea and parallel gastro-oesophageal reflux event during the night. The synchronous presentation of electroencephalogram (EEG), electro-oculogram (EOG), electromyogram submentalis (EMG), respiration (oronasal airflow ( $\left.V^{\prime}\right)$ and thoracic (thor) and abdominal respiratory movements (Abd)) and oesophageal $\mathrm{pH}$ allows judgement of the temporal coincidence between reflux event, arousal and apnoeic events. $\mathrm{Sa}_{\mathrm{a}} \mathrm{O}_{2}$ : arterial oxygen saturation.

According to the criteria of JOHNSON and DEMEESTER [15] and SCHINDLEBECK et al. [2], a pH recording was scored as pathological if the percentage of time with a $\mathrm{pH}$ of $<4$ was $>10.5 \%$ in the upright position or if the percentage of time with a $\mathrm{pH}$ of $<4$ was $>6.0 \%$ in the supine position. A single reflux event was rated as such if the $\mathrm{pH}$ dropped below 4 for $\geq 30 \mathrm{~s}$. The $\mathrm{pH}$ recording was performed for $24 \mathrm{~h}$ in each patient. The result of the $24 \mathrm{~h}$ analysis allowed a comparison of daytime and night-time (time between lights out and lights on in the sleep laboratory) events with respect to their total number and duration. A detailed analysis of all events occurring during the night followed. Different sleep stages were often found in the time course of reflux events. It was decided to attribute the reflux to the sleep stage which occurred for the largest percentage of time during the event. In addition, whether there was an arousal or transition to wakefulness during the $60 \mathrm{~s}$ before and after the reflux event was checked.

The Wilcoxon signed-rank test was used for statistical analysis. Statistical significance was assumed at a p-value of $<0.05$.

\section{Results}

Diagnostic polysomnography revealed moderate-to-severe obstructive sleep apnoea in all patients. The results are summarized in table 2. The mean AHI was 30.1 events. $\mathrm{h}^{-1}$. Those patients with an AHI of $<20$ were heavy snores. In all patients, the REI was $>20$ events.h sleep time ${ }^{-1}$.

The mean number of arousals in all patients was $265 \pm$ 155 per patient. Of these, $208 \pm 161$ (78\%) followed a respiratory event. A mean of $26 \pm 9$ transitions to wakefulness were found per patient. Of these, $15 \pm 9$ (58\%) followed a respiratory event.
A total of five patients reported symptoms of gastrooesophageal reflux during the day when interviewed on this specific point. Three of these patients also reported nocturnal reflux symptoms. The $\mathrm{pH}$ recordings revealed reflux events during the day in all 15 patients (table 1 ). Four of them had a $\mathrm{pH}$ of $<4$ for a pathological percentage of time. During the day, all patients exhibited reflux events. During the night, a total of 69 reflux events were recorded in eight patients. These included the three patients who reported nocturnal reflux. Events occurred significantly more often during the day than at night $(\mathrm{p}<$ $0.001)$.

The 69 nocturnal gastro-oesophageal reflux events were evaluated in detail with respect to the underlying sleep stage and their coincidence with respiratory events and with arousals (table 2). Thirty-one of 69 reflux events were rated as occurring during wakefulness after sleep onset. The percentage of time with a $\mathrm{pH}$ of $<4$ during WASO was significantly higher than that during TST $(p<0.05)$. Six events occurred during sleep stage 1,22 during sleep stage 2, three during sleep stages 3 or 4 and seven during rapid eye movement sleep.

For the evaluation of the coincidence with arousals and transitions to wakefulness, both were summarized as wake reactions. Seventeen reflux were found while the patient was awake after sleep onset for $\geq 1 \mathrm{~min}$. Fifty-one events were found in close coincidence with wake reactions. The reflux started directly before, during or within 1 min after a wake reaction. Only one reflux during sleep stage 2 was found without any arousal. In this case, the patient snored continuously without desaturation (fig. 2).

The 52 reflux events which were found in different sleep stages were investigated with respect to coincidence with sleep-related breathing disorders. In 37 events within 1 min 
Table 2. - Evaluation of arousal and transitions to wakefulness with concomitant evaluation of respiratory events and gastro-oesophageal reflux (GOR) events in all patients who had nocturnal reflux events

\begin{tabular}{|c|c|c|c|c|c|c|c|c|c|c|}
\hline $\begin{array}{l}\text { Patient } \\
\text { No. }\end{array}$ & $\begin{array}{c}\text { Time in } \\
\text { bed } \\
\text { min }\end{array}$ & $\begin{array}{l}\text { Total sleep } \\
\text { time } \\
\text { min }\end{array}$ & $\begin{array}{c}\text { Apnoeas }+ \\
\text { hypopnoeas } \\
n\end{array}$ & Arousals & $\begin{array}{c}\text { Arousals } \\
\text { with SRBD } \\
n\end{array}$ & $\begin{array}{c}\text { Transitions } \\
\text { to wake } \\
n\end{array}$ & $\begin{array}{c}\text { Transitions } \\
\text { to wake } \\
\text { with SRBD } \\
n\end{array}$ & $\begin{array}{c}\text { GOR } \\
\text { events } \\
n \\
n\end{array}$ & $\begin{array}{c}\text { GOR } \\
\text { during } \\
\text { WASO } \\
\% \text { WASO }\end{array}$ & $\begin{array}{c}\text { GOR } \\
\text { during TST } \\
\% \text { TST }\end{array}$ \\
\hline 1 & 460 & 280 & 177 & 206 & 151 & 22 & 12 & 24 & 18.3 & 23.6 \\
\hline 4 & 410 & 346 & 92 & 155 & 126 & 29 & 20 & 9 & 19.6 & 2.6 \\
\hline 6 & 457 & 430 & 715 & 709 & 687 & 15 & 11 & 3 & 0.0 & 0.8 \\
\hline 7 & 457 & 363 & 55 & 181 & 147 & 22 & 5 & 4 & 2.4 & 0.3 \\
\hline 8 & 440 & 407 & 74 & 269 & 167 & 29 & 13 & 3 & 36.9 & 5.7 \\
\hline 9 & 430 & 366 & 120 & 176 & 124 & 29 & 16 & 11 & 61.8 & 4.4 \\
\hline 12 & 327 & 301 & 243 & 354 & 337 & 27 & 24 & 11 & 34.5 & 6.6 \\
\hline 13 & 450 & 398 & 328 & 192 & 116 & 12 & 10 & 4 & 7.4 & 1.0 \\
\hline Mean & $429 \pm 44$ & $361 \pm 52$ & $226 \pm 218$ & $280 \pm 185$ & $232 \pm 197$ & $23.1 \pm 6.7$ & $13.8 \pm 6.0$ & $8.6 \pm 7.1$ & $22.6 \pm 20.9$ & $5.6 \pm 7.6$ \\
\hline
\end{tabular}

SRBD: sleep-related breathing disorders; WASO: wakefulness after sleep onset; TST: total sleep time.

before the drop in $\mathrm{pH}$, a respiratory event was found. During 15 reflux events, patients snored continuously without desaturation. No significant relation between the occurrence of respiratory events and reflux events was found.

\section{Discussion}

The occurrence of gastro-oesophageal reflux and possible mechanisms were studied in 15 patients with severe sleep apnoea or heavy snoring. All patients experienced reflux events during the day and eight patients at night. The percentage of time with a $\mathrm{pH}$ of $<4$ during the day was significantly higher than that during the night. During the night, it was significantly more likely that reflux events during wakefulness would be found after sleep onset than during sleep. A significant relation between the occurrence of reflux events and respiratory events was not seen.
Only five patients reported symptoms of reflux. However, reflux events during the day were found in all patients, and seven patients even exhibited a pathologically increased percentage of time with reflux, either during the day or night. This means that gastro-oesophageal reflux disease in the patients in the present study were more common than in the general population. The data from sleep apnoea patients also confirm the finding that reflux events are more common during the day than during the night $[5,10,16]$. SchindLEBECK et al. [2] reported that the likelihood of nocturnal reflux is eight times lower than that of daytime reflux. In the present study, eight patients exhibited nocturnal reflux, and, in five of these patients, the percentage of time with a $\mathrm{pH}$ of $<4$ was pathological. It was found that it was more likely for nocturnal reflux to occur during WASO than during sleep. Nevertheless, a

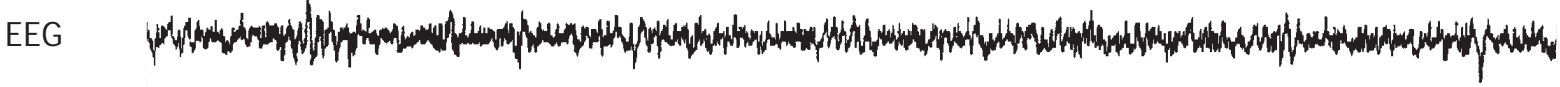

\section{EOG

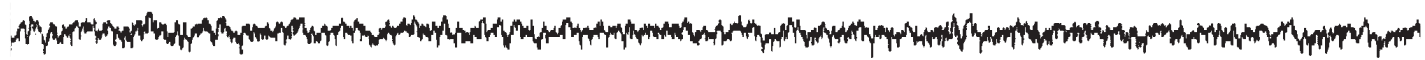

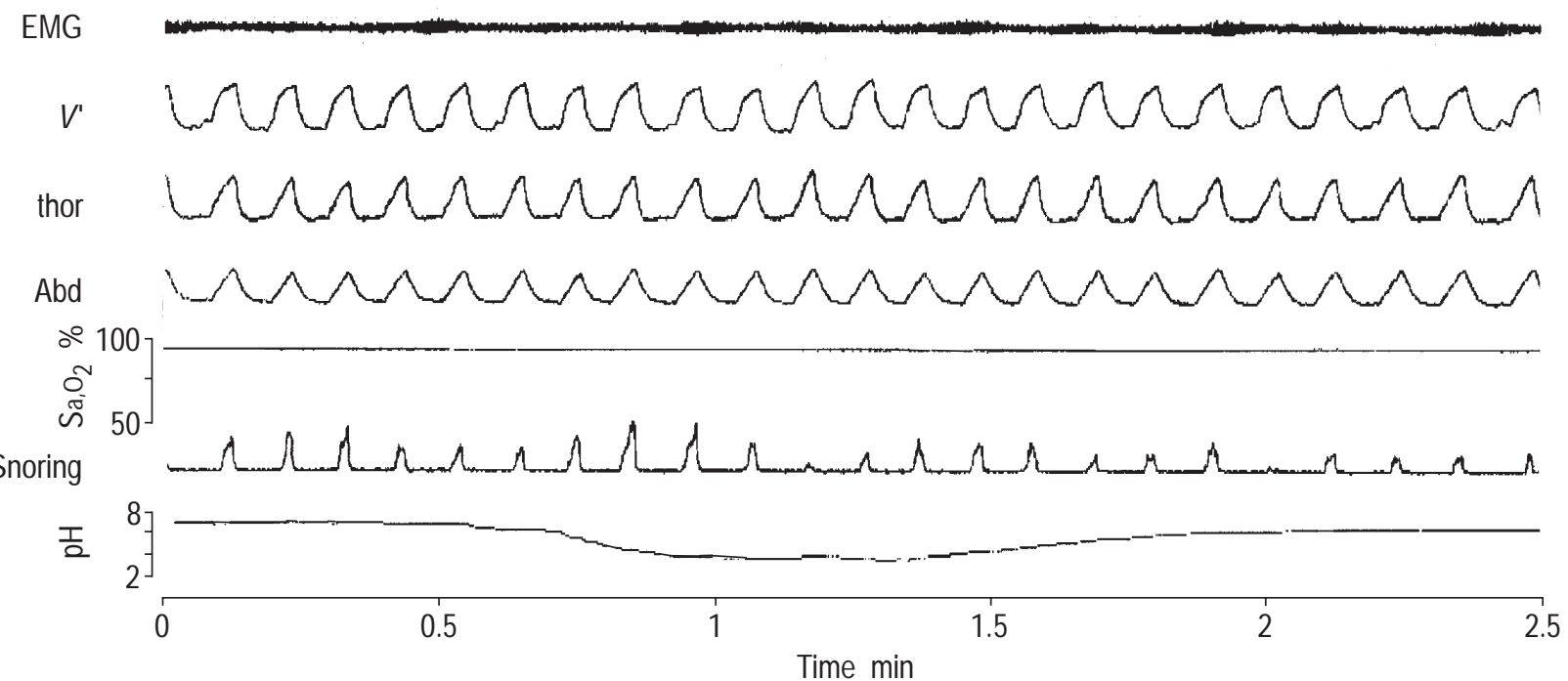

Fig. 2. - The single gastro-oesophageal reflux event in sleep stage 2 without arousals and without respiratory events is depicted. The signal of the laryngeal microphone shows the continuous snoring during this episode. EEG: electroencephalogram; EOG: electro-oculogram; EMG: electromyogram submentalis; $V^{\prime}$ : oronasal airflow; thor: thorax; Abd: abdomen; $\mathrm{Sa}, \mathrm{O}_{2}$ : arterial oxygen saturation; $\mathrm{pH}$ : oesophageal $\mathrm{pH}$. 
high number of events occurred while patients were sleeping. With the exception of one event, all of them where associated with arousal or even awakening. TARDIF et al. [17] also found that, of 15 reflux events, only one reflux occurred without a wake reaction.

The definition of reflux events given by SCHINDLEBECK et al. [2] (a $\mathrm{pH}$ of $<4$ for $\geq 30 \mathrm{~s}$ ) was used. Thus, reflux events of shorter duration were not included. However, whether or not there was a relation with $\mathrm{pH}$ drops that were shorter or during which the $\mathrm{pH}$ did not drop below 4 was checked but no relation between these reflux events and apnoeas, hypopnoeas or obstructive snoring was found (see fig. 1).

In a previous study, six patients with gastro-oesophageal reflux and obstructive sleep apnoea were treated with nasal CPAP and a significant reduction in the number of reflux events was found [9]. The high number of reflux events in patients with sleep apnoea was attributed to the negative intrathoracic pressure that occurs during apnoeas and hypopnoeas. However, the study does not provide data to support this hypothesis.

Standard definitions for the classification of arousal were used in the present study [14]. An arousal was detected between $1 \mathrm{~min}$ before and $1 \mathrm{~min}$ after the drop in $\mathrm{pH}$ in 51 of the 52 reflux events during sleep. However, arousals were caused by the respiratory events and were not associated with the beginning of the reflux. It might be worth considering more sensitive arousal markers such as cardiac frequency and blood pressure, in order to further check whether these reveal autonomous nervous system activation at the beginning of each reflux event.

One aim of the present study was to investigate the time relation between respiratory events and gastro-oesophageal reflux. In 37 of 52 periods of reflux a respiratory event was found within $1 \mathrm{~min}$ before the drop in $\mathrm{pH}$. Snoring occurred during the other reflux events. Considering the high number of respiratory events in the present patients, it is obvious that, in most cases, respiratory events were found prior to reflux events. However, most apnoeas/hypopnoeas did not induce reflux events in the patients. Thus, a causal relation between respiratory events and acid reflux could not be demonstrated.

The results indicate that gastro-oesophageal reflux in patients with sleep-related breathing disorders is not simply induced by negative intrathoracic pressure. A causal relation between apnoeas/hypopnoeas and reflux events was not seen. The question remains as to why reflux is much more common in sleep apnoea patients than in the general population. Obesity is common in patients with reflux and in patients with obstructive sleep apnoea. It may be hypothesized that obesity is a very important factor in the development of reflux. To prove this hypothesis, a larger study comparing patients with and without obesity is required. The present data indicate that obesity most probably promotes or aggravates a weakness of the lower oesophageal sphincter. In these cases, negative intrathoracic pressure due to the concomitant obstructive sleep apnoea favours the occurrence of reflux, but is not its cause. This can be prevented by effective treatment of sleep-related breathing disorders and would explain the beneficial effect of nasal continuous positive airway pressure ventilation on gastro-oesophageal reflux in patients suffering from both disorders [9, 18, 19].

\section{References}

1. Evans DF. Twenty-four hour ambulatory oesophageal $\mathrm{pH}$ monitoring: an update. Br J Surg 1987; 74: 157-161.

2. Schindlebeck NE, Heinrich C, König A, Dendorfer A, Page F, Müller-Lissner SA. Optimal thresholds, sensitivity and specifity of long term $\mathrm{pH}$-metry for the detection of gastrooesophageal reflux disease. Gatroenterology 1987; 93: 85-90.

3. Wienbeck M, Barnert J. Epidemiology of reflux disease and reflux oesophagitis. Scand J Gastroent 1989; 24: 7-13.

4. Young T, Palta M, Dempsey J, Skatrud J, Weber S, Safwan B. The occurrence of sleep-disordered breathing among middle-aged adults. N Engl J Med 1993; 328: 1230-1235.

5. Demeester TR, Johnson LF, Joseph GJ, Toscano MS, Hall AW, Skinner DB. Patterns of gastrooesophageal reflux in health and disease. Ann Surg 1976; 184: 459-470.

6. Freidin N, Fisher MJ, Taylor W, Boyd D, Surratt P, McCallum RW, Mittal RK. Sleep and nocturnal acid reflux in normal subjects and patients with reflux oesophagitis. Gut 1991; 32: 1275-1279.

7. Tardiff C, Pasquis P, Samson-Dollfus D, Denis P, Verdure-Poussin A. Reflux Gastro-oesophagien et sommeil de nuit chez l'adulte: methode et resultants obtenus chez les sujects sains. Rev EEG Neurophysiol Clin 1986; 16: 49-54.

8. Orr WC, Robinson MG, Johnson LF. Acid clearing during sleep in patients with oesophagitis and controls. Dig Dis Sci 1981; 26: 423.

9. Kerr P, Shoenut JP, Millar T, Buckle P, Kryger MH. Nasal CPAP reduces gastroesophageal reflux in obstructive sleep apnoea syndrom. Chest 1992; 101: 1539-1544.

10. Rasche K, Sanner B, Schäfer T, May B. Schlaf, Atmung und gastroösophagealer Reflux. Dtsch Med Wschr 1997; 122: 659-663.

11. Penzel T, Amend G, Meinzer K, Peter JH, von Wichert P. MESAM: A heart rate and snoring recorder for detection of obstructive sleep apnoea. Sleep 1990; 13: 175-182.

12. Värri A, Penzel T, Brandenburg U, Peter JH. Interactive computer program for the analysis of cardiovascular polysomnographic recordings.Pneumologie 1995;49:108-112.

13. Rechtschaffen A, Kales A. A manual of standardized terminology, techniques and scoring for sleep stages of human subjects. Brain Information Service, Univ. of Calif. Los Angeles.

14. ASDA Report. EEG Arousals: scoring rules and examples. Sleep 1992; 15: 173-184.

15. Johnson LF, Demeester TR. Twenty-four-hour $\mathrm{pH}$ monitoring of the distal oesophagus. A quantitative measure of gastrooesophageal reflux. Am J Gastroenterol 1974; 62: 325-332.

16. Orr WC, Shamma-Othman Z, Allen M, Robinson MG. Oesophageal function and gastrooesophageal reflux during sleep and waking in patients with chronic obstructive pulmonary disease. Chest 1992; 101: 1521-1525.

17. Tardif C, Denis P, Verdure-Poussin A, Hidden F, Pasquis $\mathrm{P}$, Samson-Dollfus D. Reflux gastro-oesophagien pendent le sommeil chez l'obèse. Neurophysiol Clin 1988; 18: 323-332.

18. Diaz S, Esteban E, Piro JM, Prados G, Villasante C. Utility of CPAP in gastrooesophageal reflux. Chest 1990; 97: 1275.

19. Konermann M, Sanner B, Kopp H, Burmann-Urbanek M. Häufigkeit des gastroösophagealen Refluzes bei Patienten mit Hypersomniesymptomatik ohne Nachweis einer schlafbezogenen Atmungsstörung. Somnologie 1998; 2: 3-7. 